\title{
Anodic Polymerization of Vinyl Ethylene Carbonate in Li-Ion Battery Electrolyte
}

\author{
Guoying Chen ${ }^{\mathrm{a}, *}$, Guorong V. Zhuang ${ }^{\mathrm{b}, *, \mathrm{z}}$ Thomas J. Richardson ${ }^{\mathrm{a}, *}$, Gao Liu ${ }^{\mathrm{a}, *}$, \\ and Philip N. Ross, Jr. ${ }^{\text {b,* }}$ \\ Environmental Energy Technologies Division ${ }^{\mathrm{a}}$ and Materials Sciences Division ${ }^{\mathrm{b}}$ \\ Lawrence Berkeley National Laboratory \\ University of California \\ Berkeley, CA 94720
}

\begin{abstract}
A study of the anodic oxidation of vinyl ethylene carbonate (VEC) was conducted with post-mortem analysis of reaction products by ATR-FTIR and gel permeation chromatography (GPC). The half-wave potential $\left(\mathrm{E}_{1 / 2}\right)$ for oxidation of VEC is ca. $3.6 \mathrm{~V}$ producing a resistive film on the electrode surface. GPC analysis of the film on a gold electrode produced by anodization of a commercial Li-ion battery electrolyte containing $2 \% \mathrm{VEC}$ at $4.1 \mathrm{~V}$ showed the presence of a high molecular weight polymer. IR analysis indicated polycarbonate with alkyl carbonate rings linked by aliphatic methylene and methyl branches.
\end{abstract}

\footnotetext{
*Electrochemical Society Active Member

${ }^{\mathrm{Z}}$ Email: GVZhuang@1bl.gov (GVZ)
} 


\section{Introduction}

Electrolyte additives are an important part of Li-ion battery technology yet their role in the battery chemistry is often not understood. Prominent among these additives are those that appear to improve the selectivity of the electrolyte reduction chemistry on graphite electrodes, allowing the use of propylene carbonate (PC) based electrolytes versus the more established ethylene carbonate (EC) based electrolytes. PC based electrolytes are attractive for automotive applications in particular because of their superior low temperature conductivity [1-3]. Although there are numerous compounds in the patent literature that are claimed to have such properties, only a few have been studied and discussed in publications. Examples are ethylene sulfite [4], and the unsaturated carbonates vinylene carbonate (VC) [5-10] and vinyl ethylene carbonate (VEC) [11-12]. The electrochemical reduction of both VC and VEC has been studied in some detail, including quantum chemical calculations of the energetics that identified the most probable reaction pathway [13-14]. Both VC and VEC appear to be reduced at potentials above $1.0 \mathrm{~V}\left(\mathrm{vs} . \mathrm{Li} / \mathrm{Li}^{+}\right)$and form a passivating film that prevents solvent cointercalation and exfoliation of the graphite at lower potentials [6-7, 11]. However, these studies have focused on the reduction chemistry of VC and VEC without discussing the anodic stability of the additive. The chemical stability of $\mathrm{VC}$ is a concern [5], and the stabilizers typically added to $\mathrm{VC}$ have oxidation potentials in the $3.5-4.0 \mathrm{~V}$ region. $\mathrm{Hu}$ et al. [11] proposed that VEC was more stable than VC and demonstrated that it functioned successfully as a film forming additive in PC based electrolyte. Vollmer et al. [12] examined the reduction chemistry of EC, PC and VEC using quantum chemical Density Functional Theory and concluded that the reduction potential of VEC is ca. $+1 \mathrm{~V}$ 
more positive than that of $\mathrm{EC}$ or $\mathrm{PC}$, indicating that $\mathrm{VEC}$ would probably be preferentially reduced to form a passivating film. VEC was, therefore, studied as an additive to the GEN2 electrolyte in the U.S. Department of Energy Advanced Technology Development (ATD) program. Descriptions of the ATD program [15] and cell chemistry [16] have been reported previously, along with a number of post-mortem diagnostic studies [16-18].

In the present work, we report on a study of the anodic stability of VEC additive after finding some anomalous characteristics in the 18650 cell with the $2 \mathrm{wt} \%$. VEC additive. As with other cells in the ATD GEN2 program, the cell was assembled and preconditioned at Quallion and shipped to LBNL in the fully discharged state. Prior to shipping to LBNL, the cell was discharged to $2.7 \mathrm{~V}$ at the $\mathrm{C} / 1$ rate. The cell was opened as-received in a glovebox at LBNL and individual components removed for diagnostic analysis. During FTIR analysis of the graphite anode, we noticed that it was unusually (versus baseline Gen 2 anodes) reactive and possibly still contained active lithium, as confirmed by fast growth of significant thick $\mathrm{Li}_{2} \mathrm{CO}_{3}$ layer upon expose to air. This was in fact found to be the case, as we report here, on subsequent studies of the chemistry of VEC that caused this anode to contain residual lithium after a $\mathrm{C} / 1$ rate discharge to $2.7 \mathrm{~V}$. We show that during the formation cycles VEC is anodically polymerized at the cathode, producing a resistive film on the active material. This may result in polarization and incomplete discharge at the relatively high $\mathrm{C} / 1$ rate. The anodic instability of VEC would appear to disqualify it as an effective electrolyte additive for high rate Li-ion battery applications. 


\section{Experimental}

The anode, composed of 92 wt.\% Mag-10 graphite (Mitsubishi) and 8 wt.\% polyvinylidene difluoride (PVDF) binder, was harvested from an ATD 18650 Li-ion cell that was assembled and went through formation at Quallion. Prior to shipping to LBNL, it had been discharged at $\mathrm{C} / 1$ rate to $2.7 \mathrm{~V}$. This particular cell had been assembled using electrolyte:1.2 $\mathrm{M} \mathrm{LiPF}_{6}$ in ethylene carbonate (EC) and ethyl methyl carbonate (EMC) $(3: 7 \mathrm{w} / \mathrm{w})($ denoted as Gen2 electrolyte) with 2 wt. \% vinyl ethylene carbonate (VEC). The residual discharge capacity, i.e. electrochemically active Li content, of the harvested anode $\left(1.4 \mathrm{~cm}\right.$ dia., $\left.1.6 \mathrm{~cm}^{2}\right)$ was measured in Gen2 electrolyte with Celgard $3401(25 \mu \mathrm{m}$ thick, Celgard Inc.) as the separator $\left(1.9 \mathrm{~cm}\right.$ dia., $\left.2.8 \mathrm{~cm}^{2}\right)$, Li metal as a counter and reference electrode, stainless steel current collectors $(1.9 \mathrm{~cm}$ dia.) and a polypropylene union fittings (Cole-Parmer). A slight axial pressure was applied to the test electrode by an internal, stainless steel spring (0.95 cm dia.). The cell was assembled in a He-filled glove box with oxygen content $<1 \mathrm{ppm}$ and water $<5$ ppm. Residual lithium was extracted from the graphite anode at a constant current of $10 \mu \mathrm{A}(\mathrm{C} / 40$ rate $)$ until its potential reached $1.0 \mathrm{~V}$. The electrode was then recharged to $20 \mathrm{mV}$ at a $\mathrm{C} / 25$ rate, and finally discharged again at $10 \mu \mathrm{A}$ to determine its nominal (low rate) capacity.

A gold $(\mathrm{Au})$ inert electrode $(99.999 \%, 1$ mil thick, $1.4 \mathrm{~cm}$ dia.) was used to study the electrochemical properties of the VEC additive. Two identical "Swagelok" cells were assembled in the glovebox, with Celgard 3401 separators (1.9 $\mathrm{cm} \mathrm{dia.)}$ and Li metal (1.9 cm dia.) as counter and reference electrodes. The cells were cycled in Gen2 electrolytes with or without 2 wt.\% (0.2 M) VEC (Aldrich, >99\%), under otherwise identical conditions. A constant current of $10 \mu \mathrm{A}$ was applied to each cell until the 
potential of the Au electrode reached $4.1 \mathrm{~V}$, and the potential was then held at $4.1 \mathrm{~V}$ until the current dropped below $2 \mu \mathrm{A}$. After one hour at open circuit potential, the cells were disassembled in the glovebox. The separators were peeled from the Au electrodes and the volatile EMC component was allowed to evaporate in the glove box prior to FTIR analysis. As a control, another Au electrode was simply stored in Gen2 electrolyte for several days in the glovebox, then dried and analyzed in the same manner as the electrode from the cells.

The $\mathrm{Au}$ electrodes were transferred from the glovebox to the helium-purged sample chamber of the FTIR spectrometer using a portable vacuum carrier. The measurements were performed on the sample surface, before and after rinsing with dimethyl carbonate (DMC), in attenuated total reflection (ATR) mode as described in Ref. 18. All spectra were acquired at a resolution of $4 \mathrm{~cm}^{-1}$, and were summed over 512 scans.

Cyclic votalmmetry (CV) was carried out using an EG\&G 273A potentiostat, at $10 \mathrm{mV} / \mathrm{s}$ scan rate between $3.0-4.1 \mathrm{~V}$, in a single-compartment three-electrode cell in the glovebox. The glass cell was sealed to prevent evaporation of the volatile electrolyte components. The working electrode was Au foil $(1 \mathrm{~cm} \mathrm{x} 1.5 \mathrm{~cm})$, counter and reference electrodes were $1.5 \mathrm{~mm}$ thick Li foil.

For gel permeation chromatography (GPC), the film was solvent-stripped from the Au surface with DMC. After allowing the DMC evaporate in glove box, the gel like substance thus obtained was further diluted in tetrahydrofuran (THF) for GPC analysis. The molecular weights of polymers were determined by gel permeation chromatography (GPC) using a PLgel $20 \mu \mathrm{m}$ Mixed B column and an Agilent 1100 Series differential 
refractometer detector at $40^{\circ} \mathrm{C}$. The lower mass detection limit for this detector is about $700 \mathrm{amu}$. THF was used as the eluting solvent at a flow rate of $0.33 \mathrm{~mL} / \mathrm{min}$, and monodisperse polystyrene standards were used to calibrate the molecular weight. The concentration of the polymer solutions used for GPC measurements depended on the amount generated during cell operation.

\section{Results and Discussion}

Residual capacity of the graphite anode

The low rate $(\mathrm{C} / 40)$ discharge profile (Figure1) of the harvested anode from 18650 cell with $2 \%$ VEC additive exhibited two voltage plateaus (insert in Fig. 1), the first with a capacity of ca. $0.1 \mathrm{mAhcm}^{-2}$ at $150-235 \mathrm{mV}$, and the second (ca. 0.05 $\mathrm{mAhcm}^{-2}$ ) at $235 \mathrm{mV}$ vs. $\mathrm{Li}^{+} / \mathrm{Li}$. The discharge curve after subsequent recharging shows the features expected for a fully lithiated graphite electrode, e.g. voltage plateaus at 100 $\mathrm{mV}, 150 \mathrm{mV}, 240 \mathrm{mV}$ corresponding to different stages of intercalation [19,20]. Using a $1 \mathrm{~V}$ cut-off, the total residual capacity of the "discharged" anode as received (after formation in electrolyte with VEC additive) was $0.27 \mathrm{mAhcm}^{-2}$ versus a nominal capacity of $0.97 \mathrm{mAhcm}^{2}$, or a residual capacity of $27 \%$ of the nominal capacity. It is clear from comparison of the voltage plateaus that the anode in this cell, following the $\mathrm{C} / 1$ discharge at Quallion, was only partially discharged before the cell reached the $2.7 \mathrm{~V}$ cut-off. This would imply that this 18650 cell was anomalously polarized on the final $\mathrm{C} / 1$ rate discharge, leaving as much as $27 \%$ of the intercalated $\mathrm{Li}$ in the graphite anode. Since other Gen2 cells from Quallion without VEC additive did not show such residual 
capacity, the implication was that VEC had somehow caused this anomalous polarization to occur.

Cyclic voltammetry of the electrolyte at Au electrode

Figure 2a compares the cyclic voltammograms (CV) with and without $2 \%$ VEC when electrochemically scanned between 3 to $4.1 \mathrm{~V}$ at the relatively slow rate of 10 $\mathrm{mV} / \mathrm{s}$. At this slow sweep rate, the contribution to the current from the double-layer capacitance is quite small (ca. $1 \mu \mathrm{A})$. The sloping curve in the VEC-free electrolyte is due to uncompensated resistance. The $\mathrm{CV}$ of the electrolyte with VEC has additional anodic current at all potentials on both forward and reverse scans, decreasing with time and/or successive sweeps, that we attribute to anodic oxidation of the VEC. The faradaic current for oxidation in the presence of VEC during the first two sweeps was obtained by subtraction of Gen2 electrolyte CV from that of the electrolyte with VEC, as shown in Figure $2 \mathrm{~b}$. The substractively obtained $\mathrm{CV}$ indicates a half-wave potential for oxidation $\left(\mathrm{E}_{1 / 2}\right)$ of ca. 3.6 V. We postulate that oxidation of $\mathrm{VEC}$ in this potential region produced a passivating (resistive) film on the electrode surface, causing the subtractive CV to decrease on successive sweeps.

Spectroscopic investigation of anodic polymerization of VEC

Figure 3 (insert) shows the potential responses of an Au electrode after a currentstep from open circuit to a constant anodic current of $10 \mu \mathrm{A}$. When the electrode potential reached $4.1 \mathrm{~V}$, it was held at this potential and the anodic current was measured until it dropped to a nominally low level $(2 \mu \mathrm{A})$. In the absence of VEC (solid line), the potential reached $4.1 \mathrm{~V}$ within $15 \mathrm{~min}$, while with $\mathrm{VEC}$ added (dashed line) it required 35 min. On subsequent holding at $4.1 \mathrm{~V}$, the current decayed to $2 \mu \mathrm{A}$ in $25 \mathrm{~min}$. in the VEC- 
free electrolyte, with a total anodic charge of $3.1 \mu \mathrm{Ah}$. On the other hand, in VEC containing electrolyte, the current decay required $200 \mathrm{~min}$., and the total charge passed was $17.7 \mu \mathrm{Ah}$, more than 5 times greater. The Au electrodes were then removed from the cells, and the excess electrolyte on the surface was allowed to evaporate in the glovebox until the electrodes were "dry" in appearance. Any products of the electrochemical oxidation remaining on the surface of the electrode were examined by post mortem analysis.

As reported previously [21], the nearly invisible film, deposited on an inert electrode simply immersed in Gen2 electrolyte, consists of only of $\mathrm{LiPF}_{6}-\mathrm{EC}$ solvate precipitate. This is easily rinsed from the surface by DMC, leaving no IR active residue. This was also the case for electrode cycled in the electrolyte absent of VEC. On the other hand, a film was clearly visible on the electrode after anodization in electrolyte with VEC additive. The molecular weight distribution of this film analyzed by GPC is shown in Fig. 4. The film consists of species with molar masses ranging up to $10^{8}$, with the lower masses being more abundant. Such a broad range of molecular weight distribution is usually an indication of highly branched polymer, and is consistent with electrochemically-initiated polymerization, i.e. polymerization from electrochemically generated radical initiators [22].

The chemical nature of the film on the $\mathrm{Au}$ electrode after anodization in electrolyte with VEC additive was investigated in more detail by ATR-FTIR. The spectra obtained are shown in Fig. 5 divided into the two major spectral regions, $3200-2800 \mathrm{~cm}^{-1}$ (panel a) and 2000-700 $\mathrm{cm}^{-1}$ (panel b). Even prior to DMC washing, the spectrum for the electrode anodized in electrolyte with VEC (curve B in Fig.5) appears to have new 
spectral features (marked by asterisks) between $1600 \mathrm{~cm}^{-1}$ and $700 \mathrm{~cm}^{-1}$ not found on the electrode from electrolyte without VEC (curve A Fig.5), the latter closely resembling that from an electrode merely soaked in electrolyte at open circuit and attributed to solvate precipitate, i.e. EC-LiPF 6 (see discussion of solvate spectra in Song et al. [21]). As seen from spectrum C in Figure 5, the new spectral features from electrolyte with VEC were intensified by the DMC washing, during which the solvate precipitates are completely removed. It is known, both experimentally and theoretically [ 5 and references therein], that EC and EMC are oxidized on inert electrodes (like $\mathrm{Au}$ ) at potentials higher than 4.2 $\mathrm{V}$, a potential higher than used here. Therefore, it is reasonable to conclude that the features marked by arrows in spectrum C may be attributed to DMC insoluble products of VEC oxidation.

The marked features in spectrum $\mathrm{C}$ from the electrode were interpreted with the combined use of compilations of standard compounds [23], group frequency assignments [24], and quantum chemical calculations of group frequencies of candidate product molecules [23]. The detailed assignment is beyond the scope of this paper and will be presented in a more complete report on these calculations elsewhere [23]. Spectrum C has strong new features in the C-H stretching region, especially in the region near $2960 \mathrm{~cm}^{-1}$ and $2860 \mathrm{~cm}^{-1}$ with weaker but still significant new features near $3040 \mathrm{~cm}^{-1}$. The vibrational modes near $3040 \mathrm{~cm}^{-1}$ are characteristic of vinylene $\mathrm{CH}$ in an unsaturated heteroatom cyclic ring, e.g. the ring in vinylene carbonate (VC) but with lower symmetry. The features at 3010 and $2930 \mathrm{~cm}^{-1}$, common to all spectra in Fig. 5, are attributed to the methylene $\left(-\mathrm{CH}_{2}-\right)$ asymmetric and symmetric modes in a saturated heteroatom cyclic ring, e.g. in EC or PC. We note that the unique asymmetric stretch of 
the vinylene group $=\mathrm{CH}_{2}$ in VEC at $3094 \mathrm{~cm}^{-1}$ is completely absent in all of the spectra in Fig.5a. Aliphatic methylene (- $\left.\mathrm{CH}_{2-}^{-}\right)$asymmetric and symmetric modes would be found at $2930 \pm 10 \mathrm{~cm}^{-1}$ and $2850 \pm 10 \mathrm{~cm}^{-1}$, respectively, and those of aliphatic methyl $\left(-\mathrm{CH}_{3}\right)$ would be found at $2960 \pm 10 \mathrm{~cm}^{-1}$ and $2830 \pm 10 \mathrm{~cm}^{-1}$. The multiplicity of peaks near the 2860 and 2960 regions indicates that there are mixture of aliphatic methylene $\left(-\mathrm{CH}_{2}-\right)$ and methyl $\left(-\mathrm{CH}_{3}\right)$ groups in the product film. Recall that EC solvate would have been washed from the electrode by DMC, and thus none of the features in spectrum $\mathrm{C}$ in Fig. 5a can be due to EC itself. Based on analysis of the carbonyl vibrational group frequency, the strong and broad carbonyl peak at about $1804 \mathrm{~cm}^{-1}$ could not be attributed to a linear carbonate functional group (e.g. in DMC, DEC or EMC) including a linear polycarbonate $[21,24]$. Interestingly, this carbonyl peak and the peaks at 1165,1075 and $716 \mathrm{~cm}^{-1}$, align well with those of vinylene carbonate (VC), except one medium intensity peak at $1292 \mathrm{~cm}^{-1}$. Quantum chemical calculations of the vibrational frequencies of candidate molecules suggest the best assignment for $1292 \mathrm{~cm}^{-1}$ feature is one $\mathrm{CH}$ bending mode coupled with the ring breathing mode of functionalized vinylene carbonate (VC). In other words, replacement of an $\mathrm{H}$ by aliphatic methyl or methylene group on $\mathrm{VC}$ to break its symmetry would give rise to this medium intensity $1292 \mathrm{~cm}^{-1}$ feature as well as all the major vibrational frequencies observed in spectrum $C$. The two small peaks at $1464 \mathrm{~cm}^{-1}$ and $1454 \mathrm{~cm}^{-1}$ fall into group frequency region of aliphatic methyl asymmetric bending ($\mathrm{CH}_{3}$ ), $-\mathrm{CH}$ - bending and $-\mathrm{CH}_{2}$ - bending mode. The presence of these characteristic aliphatic bending modes correlates well with that of their stretching modes in $3000-2800$ $\mathrm{cm}^{-1}$ 
In combining the IR analysis and the GPC results, it appears that the DMC insoluble film formed on the $\mathrm{Au}$ electrode anodized at $4.1 \mathrm{~V}$ in electrolyte with VEC additive is polymeric, specifically a polycarbonate consisting of EC-like and VC-like carbonate rings linked by aliphatic methylene and methyl branches. All of the evidence points to anodic oxidation of VEC initiated at potentials above ca. $3.6 \mathrm{~V}$ to form the radical cation I (Fig.6), followed by loss of a proton to generate the delocalized allylic radical II, whose three resonance forms may each lead to polymers via attack on neutral carbonates. Radical II may also undergo a 1,4 H-shift rearrangement to give rise to radical III, with additional resonance forms IIIA and IIIB. Polymerization via these electrogenerated allylic radicals leads to a variety of highly branched polycarbonates. Note that delocalization of the double bond produces both EC-like and VC-like rings, consistent with all the vibrational group assignments.

\section{Conclusions}

Cyclic voltammetry at a $\mathrm{Au}$ electrode in a commercial Li-ion battery electrolyte with $2 \%$ VEC has additional anodic current in the $3-4 \mathrm{~V}$ potential region on both forward and reverse scans, decreasing with time and/or successive sweeps, that we attribute to anodic oxidation of the VEC producing a passivating (resistive) film on the electrode surface. The half-wave potential $\left(\mathrm{E}_{1 / 2}\right)$ for oxidation is ca. $3.6 \mathrm{~V}$. GPC analysis of the film produced by anodization of the electrolyte at $4.1 \mathrm{~V}$ indicated a polymer with a very wide molecular weight distribution. IR analysis confirmed the presence of polycarbonates consisting of EC-like and VC-like carbonate rings linked by aliphatic methylene and methyl branches. Their formation is believed to follow directly from anodic oxidation of VEC at potentials above ca. 3.6 V. The anomalous polarization (at 
$\mathrm{C} / 1$ rate) of the prototype Li-ion cell with $2 \%$ VEC additive in the electrolyte is attributed to the resistivity of this polymeric film formed on the cathode during the formation cycles.

\section{Acknowledgement}

This work was supported by the Assistant Secretary for Energy Efficiency and Renewable Energy, Office of FreedomCAR and Vehicle Technologies of the U.S. Department of Energy under contract No. DE-AC03-76SF00098. We thank Dr. Daniel Abraham of Argonne National Laboratory and Dr. Yong-Shou Lin of Moli Energy (Canada) Ltd. for helpful discussions. 


\section{References}

1. T. R. Jow, M.S. Ding, K. Xu, S. S. Zhang, J. L. Allen, K. Amine and G. Henriksen, J. Power Sources, 119-121, 343 (2003).

2. M. S. Ding, J. Electrochem. Soc.151, A40 (2004).

3. M. S. Ding and T. R. Jow, J. Electrochem. Soc., 151, A2007 (2004).

4. G. Wrodnig, J. Besenhard and M. Winter, J. Electrochem. Soc., 146, 470 (1999).

5. X. Zhang, J. K. Pugh and P. N. Ross, J. Electrochem. Soc., 148, E183 (2001) and references therein.

6. X. Zhang, R. Kostecki, T. J. Richardson, J. K. Pugh and P. N. Ross, J. Electrochem. Soc., 148, E1341 (2001).

7. D. Aurbach, K. Gamolsky, B. Markovsky and Y. Gofer, M. Schmdit and U. Heider, Electrochim. Acta, 47, 1423 (2002).

8. H. Ora, K. Shima, M. Ue and J. Yamaki, Electrochimica Acta, 49, 565 (2004).

9. H. Ora, Y. Sakata, Y. Otake, K. Shima, M. Ue and J. Yamaki, J. Electrochem. Soc.151, A1778 (2004).

10. H. Ora, Y. Sakata, A. Inoue and S. Yamaguchi, J. Electrochem. Soc.151, A1659 (2004).

11. H. Hu, W. Kong, H. Li, H. Huang and L. Chen, Electrochem. Comm. 6, 126 (2004).

12. J. M. Vollmer, L. A. Curtiss, D. R. Vissers and K. Amine, J. Electrochem. Soc., 151, A178 (2004).

13. Y. Wang and P. B. Balbuena, J. Phys. Chem. B, 106, 4486 (2002).

14. Y. Wang, S. Nakamura, K. Tasaki and P. B. Balbuena, J. Am. Chem. Soc., 124, 4408 (2002). 
15. J. Deppe, V. Battaglia, R.A. Sutula, F. McLamon, Battery Rsearch Pograms of the Office of Advanced Automotive Technology at the US Department of Energy, in Selected Battery Topics. Proceedings of the Symposia (Electrochemical Society Proceedings Vol.98-15). Electrochem. Soc. 1999, pp.520-8. Pennington, NJ, USA.

16. M. Herstedt, D. P. Abraham, J. B. Kerr and K. Edström, Electrochim. Acta, in press. 17. K. A. Stribel, J. Shim, E. J. Cairns, R. Kostecki, Y.-J. Lee, J. Reimer, T. J.

Richardson, P. N. Ross, X. Song and G. V. Zhuang, J. Electrochem. Soc., 151, A857 (2004).

18. G. V. Zhuang, P. N. Ross, Electrochem. Solid-State Lett. 6, A136 (2003).

19. J. Dahn, Phys. Rev. B, 44, 9170 (1991).

20. M. Winter, L.-C. Moeller and J. O. Besenhard in Lithium Batteries: Science and Technology, G.-A. Nazri and G. Pistoia, Editors, p.155, Kluwer Academic (2004).

21. S.-W. Song, G. V. Zhuang and P. N. Ross, J. Electrochem. Soc., 151, A1162 (2004).

22. P. Novák, K. Müller, K.S.V. Santhanam and H. Hass, Chem. Rev., 97, 207(1997) and references therein.

23. G. V. Zhuang and P. N. Ross, to be published.

24. Introduction to Infrared and Raman Spectroscopy, N.B. Colthup, L.H. Daly and S.E. Wiberley, $3^{\text {rd }}$ Ed., Academic Press (1990). 


\section{Figure captions}

Figure 1. (insert) Residual capacity (at $\mathrm{C} / 25$ ) of the graphite anode harvested from an 18650 cell with a Gen2 electrolyte with 2 wt.\% of VEC as an additive. Subsequent discharge curve is shown following re-charging $(\mathrm{C} / 25)$ of the electrode to $0.1 \mathrm{~V}$ vs. $\mathrm{Li} / \mathrm{Li}^{+}$.

Figure 2. a) Cyclic voltammograms of an Au foil electrode in the indicated electrolytes. Only the $1^{\text {st }}$ cycles are shown. Scan rate: $10 \mathrm{mV} / \mathrm{s}$; b) subtractive current-voltage curves (current with VEC minus current w/o VEC).

Figure 3. Time profiles of constant current followed by constant voltage anodization of the electrolyte using an Au foil electrode: solid line the Gen2 electrolyte and the dashed line representing with $2 \%$ VEC added. Insert: integrated charge.

Figure 4. Chromatogram traces of film, stripped from an Au electrode, after anodization at $4.1 \mathrm{~V}$ in Gen2 electrolyte with $2 \%$ VEC added.

Figure 5. IR spectra obtained in the ATR mode from: A) electrode after anodization at 4.1 V in Gen2 electrolyte without VEC (control sample) without washing; B) after anodization in electrolyte with VEC additive without washing; C) after washing with DMC. All spectral regions were scaled with the intensity of carbonyl peak in the 1800 $\mathrm{cm}^{-1}$ region.

Figure 6. Resonant structures of allylic radicals from VEC oxidation. 


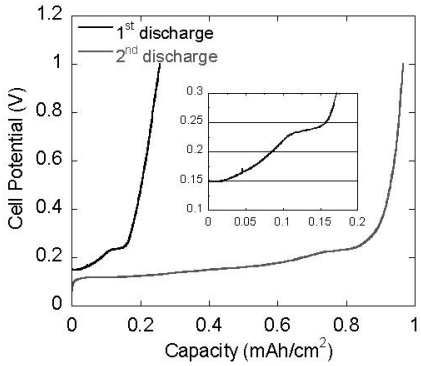



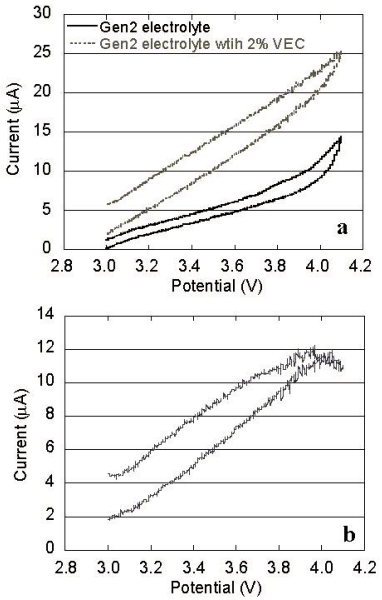


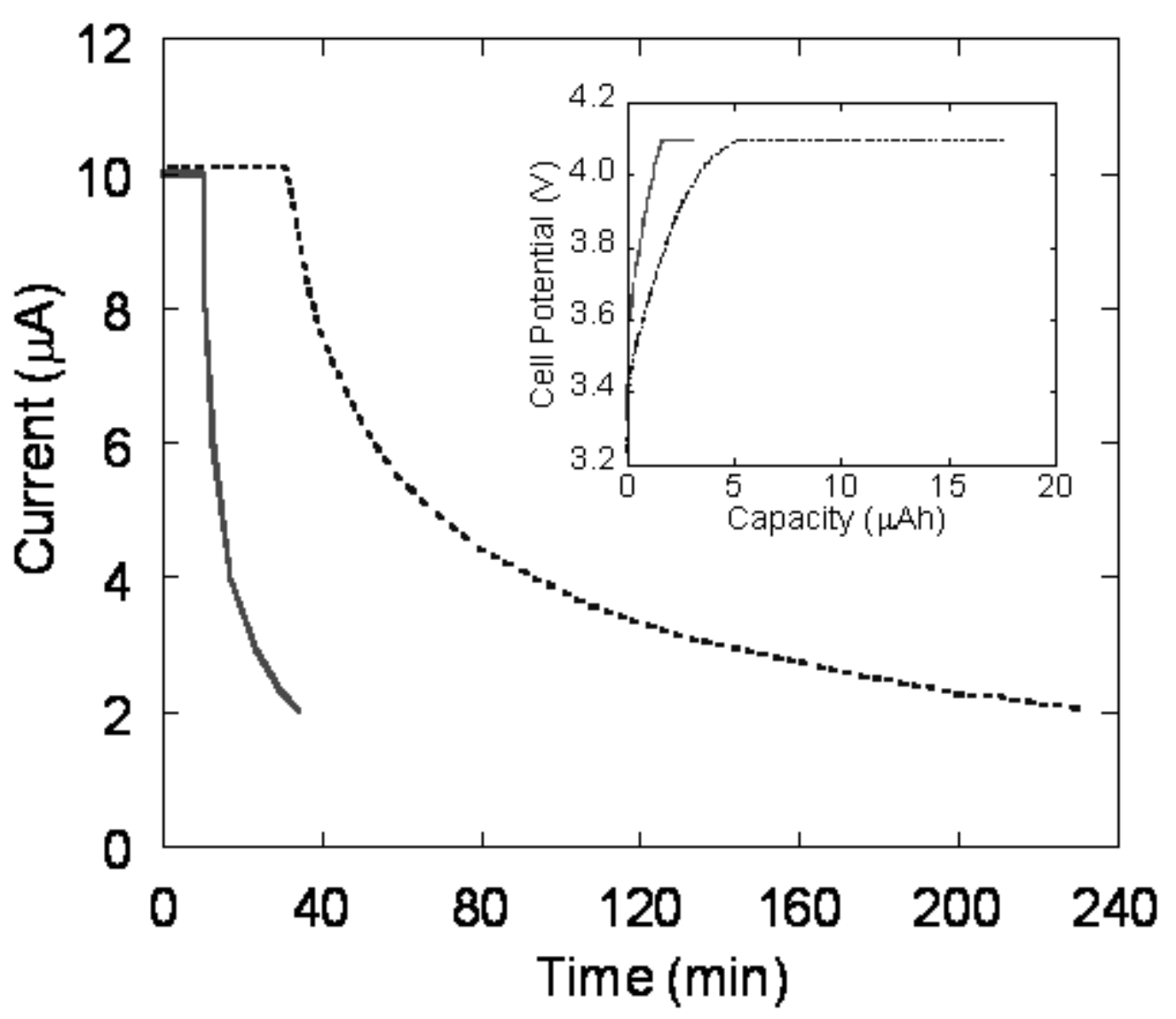




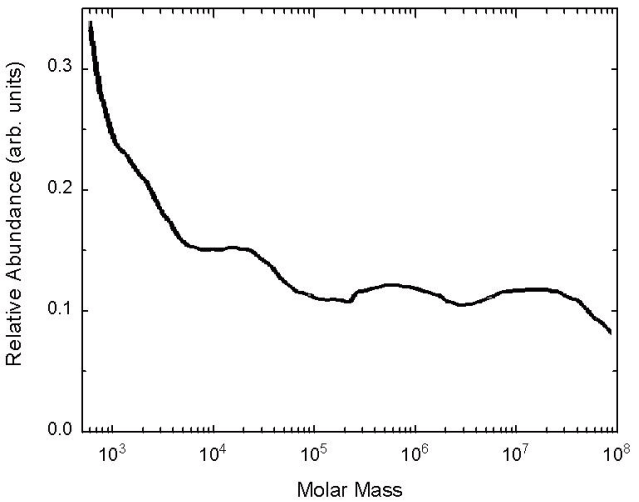




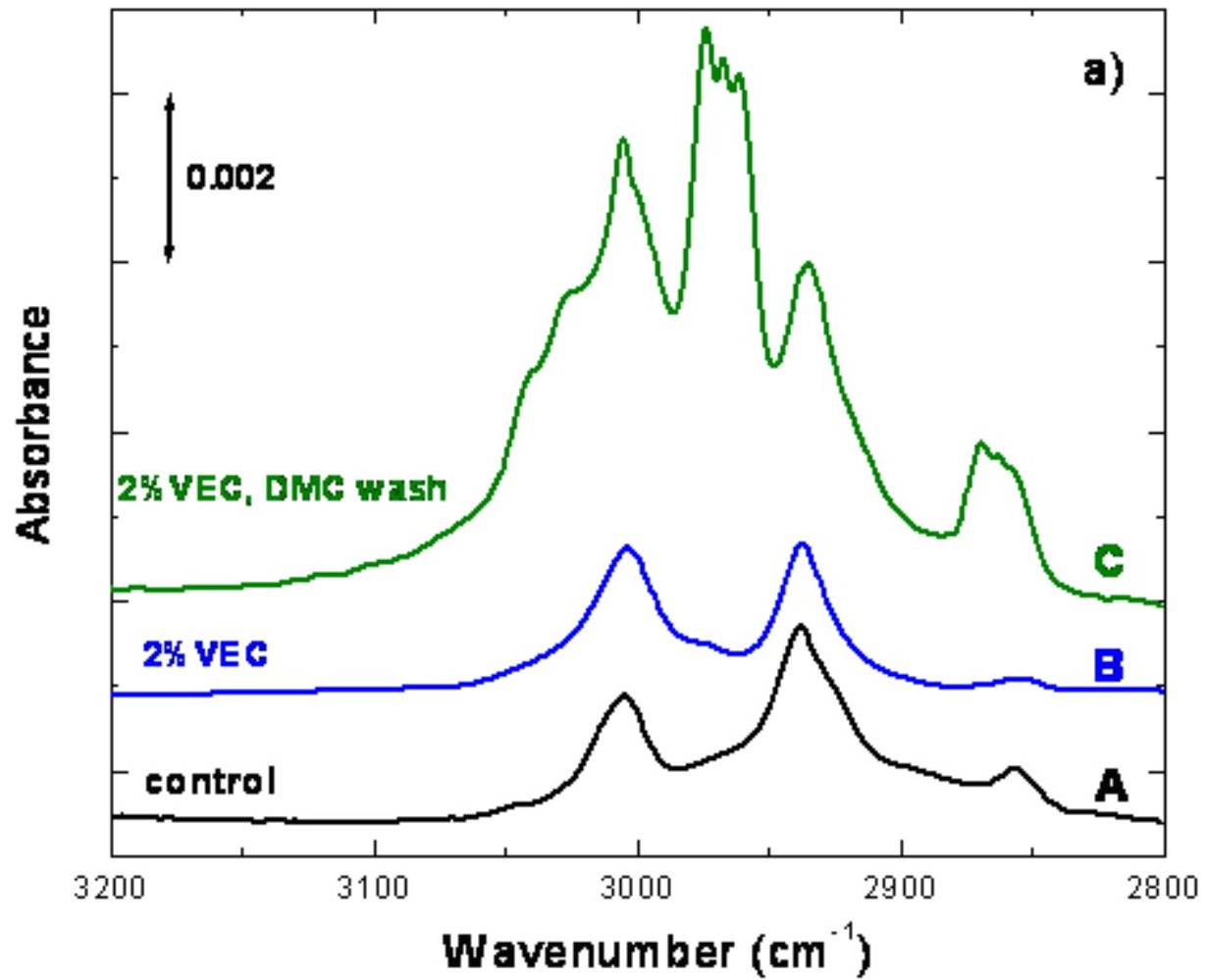




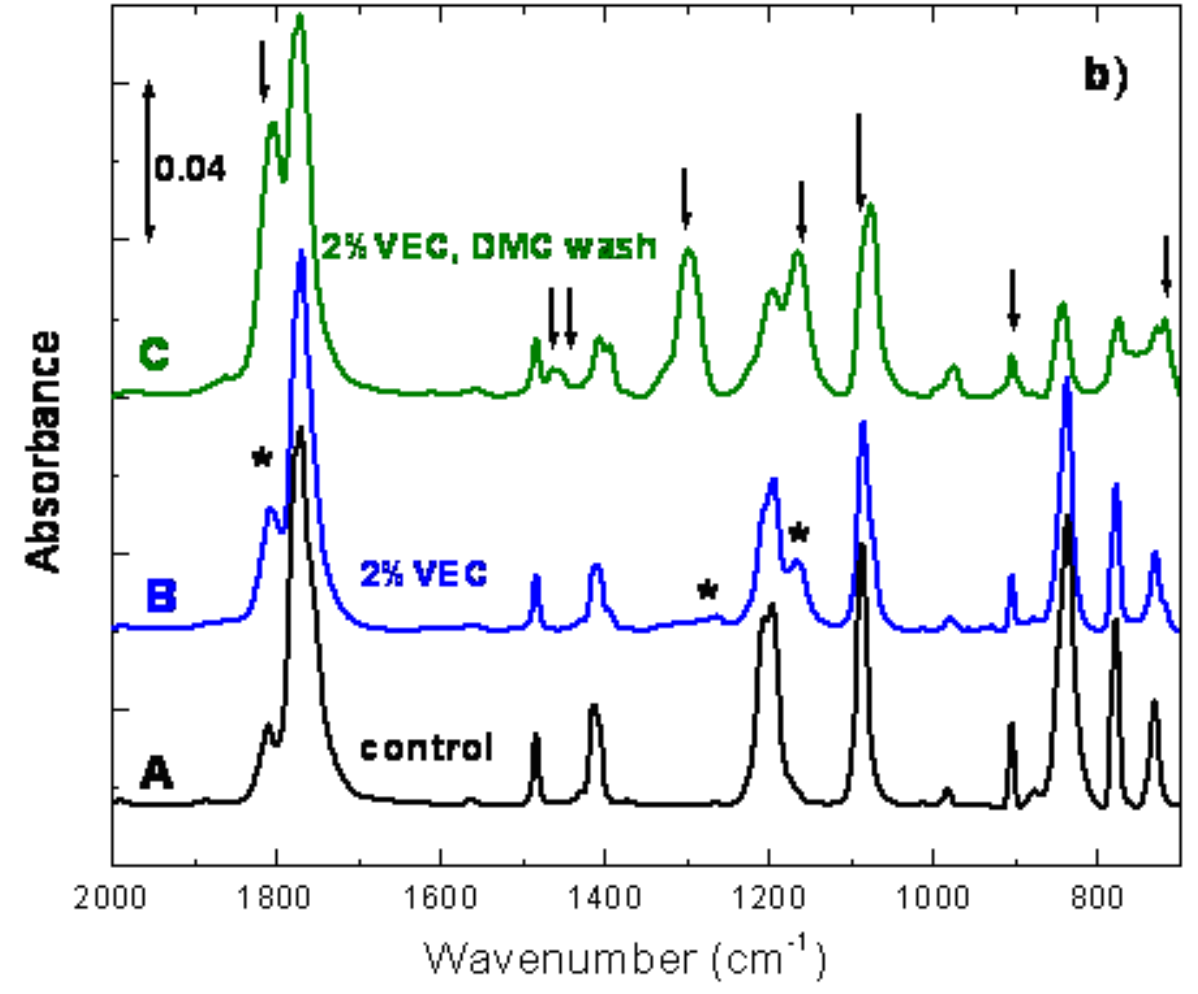


